\title{
HOW HAVE ADVANCES IN COMPARATIVE FLORAL DEVELOPMENT INFLUENCED OUR UNDERSTANDING OF FLORAL EVOLUTION?
}

\author{
Beverley J. Glover ${ }^{1}$, Chiara A. Airoldi ${ }^{2}$, Samuel F. Brockington ${ }^{2}$, Mario Fernández-Mazuecos ${ }^{2}$, \\ Cecilia Martínez-Pérez ${ }^{2}$, Greg Mellers ${ }^{2}$, Edwige Moyroud $^{2}$, Lin Taylor $^{2}$
}

\author{
Department of Plant Sciences, University of Cambridge, Downing Street, Cambridge CB2 3EA, UK \\ ${ }^{1}$ For correspondence: bjg26@cam.ac.uk, telephone 441223333938 \\ ${ }^{2}$ These authors contributed equally and author order is alphabetical.
}

\section{A. INTRODUCTION}

Evolutionary developmental biology is a discipline with a long and distinguished history. Eminent scientists such as Haeckel and D'Arcy Thompson found insight into the organismal history of morphology from an understanding of developmental programmes. However, as a modern field with a strong molecular genetic base evolutionary developmental biology has really become prevalent in the last two decades, particularly following the description of homeotic genes that appear to be linked to key morphological transitions. A primary goal of evolutionary developmental biology ("evo-devo") is to define how developmental programmes are modified to generate novel or labile morphologies. This requires an understanding of the molecular genetic basis of these programmes and of the changes they have undergone. These goals have been pursued in both plants and animals with striking insights gained in both kingdoms.

Because evo-devo is, by definition, a cross-disciplinary activity, it is conducted within a framework that often seems polarised. Evo-devo biologists with a molecular developmental background tend to consider first the genetic basis of the programme in question, before looking at the evolutionary transitions in morphology that result from it, while evolutionary biologists tend to approach the problem from the opposing position. The past decade has seen a great increase in the establishment of a common language and standards, which has greatly improved the integration of the discipline.

More recently, thanks in part to the remarkable technical advances that now enable in-depth studies to be performed on an unprecedented range of species, a more comparative approach has been added to mechanistic developmental biology. In this review we attempt to show how, by using this 'next generation evo-devo' approach, insights into both developmental and evolutionary biology can be gained. We have focused our examples on traits of the angiosperm flower, although the concepts we discuss are more broadly applicable. The review begins with a theoretical section (B), discussing the general concepts of morphological evolution and the role that developmental biology can play in providing insight into those concepts. In this initial section we discuss the origin of novel traits, the phenomenon of homoplasy and the special case of convergent and parallel evolution. In the subsequent two sections we discuss selected examples of floral traits whose comparative developmental biology has provided greater understanding of these concepts. Section $\mathrm{C}$ focuses on the origins of novel floral traits while section D considers examples of traits that are labile through evolutionary time. We hope that these examples will stimulate fresh debate and ideas about how comparative developmental analyses can inform evolutionary studies. We conclude with a brief perspective on the prospects for the future of this exciting field.

\section{B. DEVELOPMENTAL INSIGHT INTO EVOLUTIONARY CONCEPTS}

We begin this review with an overview of the potential for comparative developmental biology to provide insight into two fundamental areas of evolutionary enquiry: the origin of novel traits and the 
recurrent appearance of similarity in evolution. We highlight some conceptual issues surrounding the notion of novelty and how comparative developmental analyses can shed light on to the origin and evolution of novelty. We then discuss the phenomenon of homoplasy and the numerous ways in which developmental biology can clarify the phenomenon of homoplasious traits.

\section{Development and the Origin of Novel Traits}

Many biologists regard the origin of novel traits, or evolutionary novelties, as a core investigative theme in plant evo-devo. However, reaching a definition of the term novelty is challenging, and in that sense the consideration of developmental criteria is informative. Mayr (1963) defined an organismal novelty as any "newly acquired structure or property that permits the performance of a new function, which in turn, will open a new adaptive zone" i.e. lead to an adaptive radiation. However as Pigliucci points out, novel traits can arise without being causally linked to adaptive radiations, while features may play a role in radiations despite not being themselves demonstrably novel (Pigliucci, 2008). In a strictly phylogenetic approach, Arthur equates novelty and apomorphy (i.e. a derived feature or trait of a clade) as essentially the same (Arthur, 2000) but this definition risks conflating derived traits and apomorphic variation as novel regardless of the degree of differentiation. In this regard the definition of Muller and Wagner (1991) offers some conceptual advantages in defining novelty as "a structure that is neither homologous to any structure in the ancestral species nor serially homologous to any other part of the same structure". Similarly WestEberhard emphasizes the importance of disjunction, arguing that a novel trait should be based on "a qualitatively distinct developmental variant" (West-Eberhard, 2003). Finally, Pigliucci attempts to merge these principles, defining evolutionary novelties as "new traits or behaviours, or novel combinations of previously existing traits, arising during the evolution of a lineage, and that perform a new function within the ecology of that lineage" (Pigliucci, 2008). In the context of this review however, we will primarily use the developmental concepts of Muller and Wagner (1991) and West Eberhard (2003), as they are perhaps the most instructive in highlighting the role of developmental data in advancing our understanding of novel trait evolution. In exploring the conceptual boundaries and definitions of novelty, it is evident that developmental analyses allow insight into the evolution of novel traits from a variety of angles as outlined below.

Developmental analysis can identify novelty by revealing developmental disjunction or nonhomology. A detailed understanding of the morphological development of a structure can reveal whether it is homologous to other structures, on the basis of various criteria including its position within the organism and the structural peculiarities of the trait in question (Pigliucci, 2008). If the structure is shown to have no positional equivalent in related taxa or relative to a hypothesised ancestral state, and to be unrelated to transitional serially homologous structures within the same organism, the trait may be considered novel by the criteria of Muller and Wagner (1991).

Developmental genetic approaches can be used to explore to what extent the trait is novel at the genetic level. Often developmental studies can initially reveal that a trait may be non-homologous at the level of its morphology and structure. Yet subsequent analyses may show it to be underpinned by a genetic program that has been recruited and derived from the development of otherwise unrelated structures (Yu et al., 1999; Kramer and Irish, 1999; Sharma and Kramer, 2013).

Developmental tools can be used to assess the functional novelty of a trait. In identifying the genetic basis of novel traits, it further becomes possible to assess their functional and adaptive significance in the context of the life history of the organism. Manipulation of the underlying genetic pathways allows for modulation of the quantitative or qualitative properties of the trait. For example, such manipulations can create near isogenic lines that are identical except for the trait of interest. These can first be used to rigorously assess the function of a given trait, and whether or not the trait is currently adaptive. By subsequently sampling at the population level or between paired species, it also becomes possible to gain insight into the adaptive significance of the trait during molecular evolution instead of relying on the correlation of the trait with functional and/or organismal diversification (McGrath et al., 2011; Klahre et al., 2011).

\section{The Developmental Basis Of Homoplasy}


Homoplasy, or similarity in evolution, is a key feature of phylogenetic diversity, and a second fundamental investigative theme in plant evo-devo (Wake et al., 2011). Patterns of homoplasy can be driven by a variety of mechanisms, including the repeated gain of a character, or a character gain in an ancestral organism followed by subsequent losses or reversals in its descendants. Mapping the distribution of a given trait onto an organismal phylogeny allows testing of the evolutionary history of the trait. In turn, this allows us to infer the direction of evolutionary change by identifying whether a feature has been lost or gained, and also to identify when and where the shifts in character state occurred. In the context of molecular-based organismal phylogenetics, this process of morphological character reconstruction has revealed that many traits are remarkably labile. Studying the evolutionary history of labile traits has shown that even highly elaborate traits can arise multiple times independently, and that even those that seem to present a net selective advantage in a given context can be lost (Igic et al., 2008; Renner et al., 2010). These observations emphasise important questions regarding transitions in character evolution. Firstly is a character shift more likely to occur in one direction than another i.e. are gains more likely than losses or vice versa for any given character? Second, are evolutionary changes reversible i.e. can a trait be gained, then lost, then subsequently regained? Third, to what extent are the mechanisms underlying repeated trait evolution driven by similar genetic changes, or by entirely different molecular processes? In revealing how characters are genetically programmed across a range of species, comparative, developmental biology directly addresses these questions.

Development can highlight the mechanisms underlying the loss or gain of a trait. Although gains have been studied more than losses (Ellers et al., 2012), some developmental genetic trends are emerging. A shift in character state can be caused by mutation of a structural gene (for example, an enzyme from the biosynthetic pathway leading to pigment production) or by modification of a regulatory interaction (Rausher et al., 2008; Hoekstra and Coyne, 2007; Carroll, 2005; Carroll, 2008). For example, a transcription factor (TF) responsible for switching on or off a developmental pathway can be deleted or mutated triggering the loss of the dependent trait (e.g. AN2 locus in Petunia, Hoballah et al., 2007). Alternatively, a regulatory element in the promoter of a gene targeted by this TF can be lost or silenced (e.g. by epigenetic alterations such as DNA methylation) preventing the developmental programme from being fully executed (Gaunt et al., 2012; Weigel and Colot, 2012). Reciprocally, traits can be gained when, for instance, TFs change their DNA binding specificity or when target genes acquire new regulatory elements and assemble into gene networks that promote the development of a trait previously absent (Carroll, 2008). Trait losses and gains are not exclusively caused by a modification of regulatory interaction. For instance, gene duplications followed by neo or sub-functionalization of effector genes can also account for character evolution (Soltis et al., 2007)

Understanding the developmental processes in closely related species can be used to infer the directionality of change. Once the molecular toolkit responsible for a character state in several species is known, it becomes possible to reconstruct this toolkit in the last common ancestor of the species and deduce the condition of the ancestral state for a group of organisms (Thornton, 2004). Knowing the original state then permits us to establish whether a feature of interest has been lost or gained in independently radiating lineages. Through approaches such as these, the increasing knowledge of developmental mechanisms has questioned previous lines of evolutionary thought. For example, character losses were hypothesised to be more likely than gains because losing a trait was proposed to be easier than gaining one. However, both types of shifts can arise from similar mechanisms at the molecular level making both types of changes equally probable. For example, either a gain or loss of a regulatory element can result from a single nucleotide change in the promoter region of a given gene (Prud'homme et al., 2006). Similarly, the idea that the loss of complex traits is always irreversible has been challenged by developmental studies. Indeed, the underlying developmental pathways leading to complex traits can be retained long after the loss of the feature itself (Wiens et al., 2011; Sucena et al., 2014). A trait, even complex, can thus be occasionally regained as the genetic architecture that controls its formation is already present (Withing et al., 2003; Wake et al., 2011).

Comparative developmental data can reveal whether a trait has been lost or gained several times independently. When the phylogenetic relationships between organisms remain unclear, it can 
be difficult to establish how many times a shift in character states has occurred. Ancestral state reconstructions based on parsimony or model-based statistics are usually used to distinguish character loss versus gain, yet these methods may not give conclusive results for many characters. Evidence from developmental genetics can be useful in distinguishing between similarly supported scenarios of character change. For example if a trait has been lost or gained several times independently, the particular changes responsible for the state shift are unlikely to be identical. By pinpointing which alteration of a developmental programme is responsible for the shift at each transition, it is possible to test if the pattern observed stems from a single event or from recurring independent transitions (Wake et al., 2011).

Developmental processes can reveal innate stability or instability in certain traits due to the underlying developmental architecture. A better understanding of the developmental architecture of a trait can explain why some traits are more labile than others. Developmental data can provide insight into whether the mechanisms underlying trait development are more or less robust, why particular traits are more likely to be lost or gained as developmental constraints sometimes favour one direction (eg. loss of anthocyanin colouration, see Wessinger and Rausher, 2012; Cooley and Willis 2011) and why some state shifts are more prone to be immutable than other (eg. loss of a gene) (Igic et al., 2006). In addition, by providing information on the redundancy present in morphogenic pathways, developmental data can provide insight into the robustness and evolution of genetic networks.

Comparative developmental genetics can distinguish between mechanisms of parallel versus convergent evolution. A fundamental debate in the context of homoplasy and the observation of recurrent evolution of similar traits is the extent to which the distinct origin of traits is the result of convergent versus parallel evolutionary mechanisms. Convergence and parallelism both refer to the independent evolution of similar phenotypic traits. However, in the context of evolutionary developmental biology, parallelism describes traits that evolve separately through the same genetic modifications, whereas convergence describes the evolution of phenotypic similarity via distinct genetic pathways. In identifying the genetic pathway underlying a trait, and in studying how these pathways change across multiple evolutionary transitions leading to a particular phenotype, it becomes possible to distinguish between parallel and convergent evolution at the molecular level (Wake et al., 2011).

\section{THE ORIGIN OF NOVEL FLORAL TRAITS}

In this section of the review we explore how developmental genetics has been used to explore the evolutionary origin of novelty within the context of the angiosperm flower. We take a hierarchical approach, beginning with a discussion of the developmental genetic theories surrounding the origin of the flower itself, and subsequently addressing the origin of extra sets of floral organs (staminodes), highly derived floral organs (lodicules and pappus), and elaborated floral outgrowths (nectaries and nectar spurs).

\section{The Origin of the Flower Itself}

The most significant trait to evolve along the stem leading to the angiosperm lineage was the flower itself. The definition of a flower is the bisexual reproductive shoot, in which the reproductive organs are surrounded by series of sterile organs. Each type of reproductive or sterile organ is arranged in circular or spiral patterns forming a series of concentric rings or whorls. This points to a complex set of key innovations, including the combining of male and female reproductive structures within a small space on the same shoot as well as the production of perianth organs. Comparative developmental genetic analysis has provided insight into both of these innovations, changing the way that we think about the evolutionary origins of flowers. Here we focus on the evolution of bisexuality.

Although there are many examples of derived unisexual flowers, the ancestral angiosperm flowers produce both male and female reproductive organs. This is in marked contrast to the reproductive structures of most non-angiosperm plant lineages where unisexual reproductive structures are the 
norm. All bisexual angiosperm flowers contain an outer whorl of male reproductive organs and an inner whorl of female reproductive organs, suggesting that the evolution of bisexual flowers occurred only once (Cronk, 2001; Garay-Arroyo et al., 2012) for discussion of a possible exception more likely representing a reduced inflorescence).

The first model to take a developmental genetic approach to the evolution of bisexual flowers was the "Mostly Male Theory". In this model the bisexual shoot evolved by the production of ovules in the centre of a male cone, the cone retaining a "mostly male" identity. This hypothesis was based on analysis of sequence and expression patterns of genes predicted to regulate gymnosperm cone development, which suggested that an angiosperm gene necessary to determine the floral nature of the meristem (LEAFY) was most closely related to a gymnosperm gene involved in male but not female cone development (Frohlich and Parker, 2009). Species of Pinus, Welwitschia and Ginkgo contain two $L E A F Y$ homologs, and early data suggested that the angiosperm sequence was most similar to a male-specific gymnosperm copy. However, more recent data have shown that both gymnosperm genes can have mixed expression patterns (Dornelas and Rodriguez, 2005; Vázquez-Lobo et al., 2007; Shindo et al., 2010). Although further analysis has not supported the molecular genetic basis of the mostly male hypothesis, it is an important example of an early effort to use comparative developmental genetic data to inform evolutionary theory.

Homeotic models propose that the bisexual shoot evolved by the conversion of organs at the axis of a male cone into the female form or conversion of the organs at the base of a female cone into the male form. Homeotic conversion of organ types is usually attributed to the genes controlling floral organ development. Genes related to angiosperm stamen-defining B function genes have been isolated from conifers, and from Gnetum, and are expressed in the male cones, but not in the female cones (Sundström and Engström, 2002; Winter et al., 2002). Similarly, genes related to angiosperm stamenand carpel-defining C function genes have been isolated from Gnetum, Cycas and Picea, and shown to be expressed in both the female and male cones, indicating that homologs of $\mathrm{C}$ function genes are active in all reproductive structures in gymnosperms (Rutledge et al., 1998; Tandre et al., 1998; Zhang et al., 2004). The functions of these genes in gymnosperms remains hypothetical, but their expression patterns suggest that expression of the $\mathrm{C}$ function genes, in both angiosperms and gymnosperms, confers a reproductive identity on an organ. In angiosperms, it is expression of the B function gene that determines which sort of reproductive structure is produced, with $\mathrm{C}$ alone specifying female fate and $\mathrm{B} / \mathrm{C}$ together specifying male. Assuming that $\mathrm{B}$ and $\mathrm{C}$ functions are conserved in gymnosperms, these developmental genetic analyses provide the basis for the "Out of Male" and "Out of Female" evolutionary hypotheses. Loss of B function gene expression from the upper regions of a male axis would result in the production of female organs within whorls of male organs. Similarly, gain of B function gene expression in the lower regions of a female axis would result in the production of male organs outside whorls of female organs (Cronk et al., 2002). The implications of these developmental genetic insights into evolutionary history can be tested by exploring the occasional cases of bisporangiate cone formation in a variety of gymnosperm lineages (Endress and Steiner-Gafner, 1996; Rudall et al., 2011).

\section{The Origin of Extra Floral Organ Whorls: Staminodes}

In general the flowers of angiosperms, especially within the most speciose and derived eudicot clade, share a common bauplan with four types of floral organ (sepals, petals, stamens and carpels) arranged in successive concentric whorls. However, there are many instances among the angiosperms in which additional floral whorls have evolved with a distinct organ identity, and these novel whorls may perform specific functions in the ecology and evolution of the flower. Recently, developmental genetic studies have shed additional light on the novel origin of these structures and the genetic mechanisms underlying their phenotypic disjunction. Here, we highlight the example of staminode evolution within Ranunculaceae.

In the majority of angiosperms, the stamens differentiate into a basal supportive part, termed the filament, and an upper microsporangia-bearing tissue, termed the anther (Smets and Decraene, 2002). In those instances in which the stamens do not develop reproductive structures but retain many of the characteristics of the male reproductive structures, they are usually referred to as sterile stamens or 
staminodes. These staminodes can become highly elaborated and are hypothesized to perform distinct ecological functions in the context of the flower eg. nectar production, nectar cover or secondary pollen presentation (Smets and DeCraene, 2002). In instances where the staminodes have a highly derived morphology or novel function, an interesting question concerns how the evolutionary identity of staminodia arises as a distinct entity with respect to other floral organs. Here the case study of Aquilegia within Ranunculaceae provides important insights. Aquilegia exhibits a floral structure with five floral organ whorls encompassing an additional whorl of elaborate staminodia between the petals and stamens (Fig. 1A).

Canonical developmental genetic models have established that the combinatorial activity of several MADS-box transcription factors including the AP3, PI, and AG lineages are necessary to specify fertile stamens in model organisms. However Kramer et al. (2003) identified homologs of the AP3 and PI MADS-box genes across Ranunculaceae and showed that an ancient duplication in the AP3 lineage within Ranunculales gave rise to three distinct AP3 lineages: AP3-I, AP3-II, and AP3-III (Kramer et al., 2003). Although the significance of the paralog AP3-III will be discussed later in this review, the evolution of AP3-I and AP3-II are relevant in understanding the evolution of elaborated staminodia. Initial studies showed that although in Aquilegia, AqAP3-1 and AqAP3-II are initially expressed in common in both stamen and staminodial primordia they quickly become differentially expressed, with AqAP3-1 in the staminodia and AqAP3-II specific to the stamens (Kramer et al., 2007). Subsequent transient RNAi based methods show that $A q A P 3-1$ is predominantly involved in staminodial specification while disruption of AqAP3-II affects stamen development (Sharma et al., 2011). The evolution of these paralogous lineages predates the apparent origin of staminodia within Ranunculaceae, thus a likely scenario is that gene duplication has given rise to sub-functionalisation of the ancestral AP3 function between the stamen and staminodial whorls. Following this subfunctionalisation, further neo-functionalisation of the AqAP3-1 paralog has enabled the differential identity of the elaborated staminode to evolve (Sharma et al., 2011). With respect to the novel fifth whorl in Aquilegia, elaboration of the underlying genetic pathways through gene duplication has likely been essential to the evolution of these novel organs.

This case study from Aquilegia highlights the important role of gene duplication within key floral gene lineages followed by sub-functionalization and neo-functionalization as a mechanism to allow the independent evolution of distinct floral modules within the context of the flower. The role of gene duplication is a recurrent theme in evolutionary development with the potential to explain the origin of many morphological traits.

\section{The Evolution of Highly Derived Floral Organs: Lodicules and Pappus}

In many flowering plant lineages the morphological differentiation and functional specialisation of certain floral parts can be so dramatic that the evolutionary history of the floral organ in question becomes opaque. In this instance developmental analyses have played a vital role in understanding the homology of these structures, allowing a better understanding of the nature of the morphological divergence and evolution of the genetic pathways underlying novel evolutionary differentiation. Examples of this phenomenon from the flowering plants include the evolution of the lodicules in the grass family Poaceae, and pappus bristles found in Asteraceae. As outlined below, both structures are examples in which the developmental genetic data suggest homology to antecedent structures. With respect to our earlier discussion on definitions of novelty, these structures do not satisfy the novelty criterion of Muller and Wagner (1991) because the lodicule and pappus can be homologised with ancestral organs. However both the lodicules and pappus appear to be distinct developmental variants performing novel ecological functions in the life history of their respective organisms, and as such speak more to the criterion of novelty prescribed by West-Eberhard (2003) and Pigliucci (2008).

\section{The Lodicule}

The lodicule is an organ unique to the grasses that occurs in a whorl just outside the stamens. Lodicules can be fleshy or scale-like and generally swell at anthesis to allow the stamens to extend and the surrounding perianth-like lemma and palea to separate (Whipple et al., 2007). The rapid 
extension of the filaments at anthesis, in part driven by the action of the lodicules, is a critical aspect of the life history and ecology of grasses and associated with wind pollination (Fig. 1B). Although the lodicules are homologous in position to the petals in core eudicots, the morphology and cellular structure of the lodicule is very different. Consideration of different criteria for determining homology (structural vs positional), has generated debate as to the evolutionary origin of lodicules and the extent to which they represent novel organs. Recent comparative developmental genetic data support the homology of petals and lodicules because the lodicules, their positional equivalents in early diverging Poaceae (Elegia, Joinvillea, Streptocarpa) and the petals of core eudicots, all exhibit a similar expression domain of the B-class MADS-box transcription factors (Whipple et al., 2007). While the expression of B function genes in lodicules implies homology with petals, the nature of the genetic changes, which underlie the very different morphological outcomes of the lodicule versus the petal, are unknown. Such morphological differentiation is likely driven by changes in the regulation of the genes controlled by the B function transcription factors. Such changes could originate from differences in the B protein interacting partners or in the cis-regulatory elements of the target genes. Further studies will be necessary to elucidate how gene networks have evolved with respect to these different structures (Yoshida, 2012), because while analysis of B-gene expression allows us to understand the lodicule it does not explain what genetic changes underlie the evolution of this highly derived structure.

\section{The Pappus}

In Asteraceae a whorl of bristles, scales, or awns termed the pappus often surround the bases of the corolla tubes of individual florets within the capitulum, the specialised inflorescence in Asteraceae. The pappus plays an essential role in the dispersal of seeds within several lineages of Asteraceae (Fig. 1C). Pappus structures are unusual as they lack vascular bundles and yet, given their position at the base of the corolla, the debate has focused on whether they are highly modified inflorescence bracts or sepals. Homeotic mutant phenotypes in model Asteraceae species provide insight into the evolutionary history of the pappus. Down-regulation of B and C function genes in the model Astercaeae Gerbera hybrida changed the identity of petals and carpels into organs that resembled pappus structures, in the same way that petals and carpels are converted to sepals in B and C function mutants in Arabidopsis thaliana (Yu et al., 1999). This finding strongly suggests that pappus hairs represent sepals. The difference between sepals and the highly specialized structure of the pappus likely lies in the downstream targets and, as in the case of the lodicule, further studies will be essential to understand how the regulatory networks have evolved to produce such specialized organs. In the case of both the pappus and the lodicule we see how developmental genetic data, in the form of gene expression patterns and/or mutant phenotypes, provide additional criteria with which to explore homology and the concept of evolutionary novelty. The value of gene expression in particular has been the subject of intense debate within evolutionary developmental biology (Abouheif et al, 1997) and it is important to recognise that these genetic criteria must not be considered the sole criterion on which to establish homology, but should be considered in the context of a plurality of homology criteria (Remaine, 1962).

\section{Floral Outgrowths: Nectaries and Nectar Spurs}

Flowers offer rewards to animal pollinators in the form of nectar, pollen, and occasionally other more specialist offerings such as scented resins (Armbruster, 1988; 1992), oils (Buchmann, 1987), and fragrance (Dressler, 1982). Most rewards provide a food source which is essential for associative learning, enabling a pollinator to form a 'search image' of a previously-rewarding flower (Chittka and Thomson, 2001). The most common type of floral reward is nectar. Nectar is a secreted solution containing water, sugars, amino acids, and other chemical compounds (eg. ions, alkaloids or terpenoids). It is usually a simple attractant being an energy-rich and easily-digestible food source for animals, but it can also contain defence chemicals which act as herbivore deterrents. Given its crucial role in the pollination process, as well as its important ecological function as a food, nectar is considered to have had a major role in both angiosperm and pollinator evolution, and is associated with the evolution of two novel morphological structures: nectaries and nectar spurs.

\section{Nectaries}


Nectar is produced from nectaries, glands that are defined according to their secretory function (Fahn, 1979). Nectaries are highly variable in their morphology and occur on both vegetative and floral organs. Those housed within flowers are termed floral nectaries (Schmid, 1988), and their positioning is often crucial for luring pollinators to the correct location for pollen deposition (Fig. 1D). Floral nectaries are widespread within the angiosperms but nectary structure and placement varies greatly. This diversity suggests that there may have been multiple independent evolutionary origins of this novel structure within the angiosperms. Molecular genetic research has indicated that, at least within the core eudicots, common genetic mechanisms underlie the development of diverse nectary structures.

The YABBY transcription factor CRABS CLAW (CRC) was first identified from an Arabidopsis mutant ( $c r c$ ) lacking nectaries (Bowman and Smyth, 1999; Baum et al., 2001). CRC is expressed within the developing nectaries and gynoecium and is necessary, though not sufficient, for nectary formation (Baum et al., 2001). CRC expression is independent of the floral organ identity genes, which suggests a developmental explanation for why floral nectary positioning is not constrained by the placement of other floral organs (Baum et al., 2001). CRC homologs are found across the seed plants (including in the gymnosperms). Moreover, their spatio-temporal expression patterns in the female reproductive organs are conserved between eudicots and early diverging angiosperm species, suggesting that they are ancestral regulators of carpel development (Fourquin et al., 2005). However, it is only within the core eudicots that they have been shown to play a conserved role in nectary development (Lee et al., 2005). Lee et al. (2005) showed that $C R C$ ortholog expression is conserved within morphologically distinct nectaries from Asterid and Rosid species, and that virus-induced gene silencing within Nicotiana benthamiana can produce a similar phenotype to that of the Arabidopsis crc mutant. $C R C$ genes may therefore have been co-opted from carpel development to a nectary development role at the base of the core eudicots. The nectary consequently provides an interesting example of a trait whose labile morphology and position suggested a number of independent origins, but for which developmental genetic analysis suggests a single origin through modification of an ancient carpel development module. This ancient carpel development module can be thought of as an exaptation, a previously present unit that facilitates evolution of a particular character.

\section{Nectar Spurs}

Nectar spurs are tubular outgrowths of floral organs, usually petals or sepals, typically containing nectar, which is either secreted directly by the spur tissues or drains into the spur from nearby nectaries (Fig. 1E). Nectar spurs can be considered a key innovation or evolutionary novelty sensu Mayr as their evolutionary acquisition in disparate plant families is associated with significant bursts of species diversification linked to pollinator specialization (Hodges, 1997; Whittall and Hodges, 2007). The comparative developmental study of nectar spurs in independent lineages allows analysis of whether similar developmental mechanisms have been recruited. Spur development is being studied primarily in three systems covering a broad phylogenetic spectrum: columbines (Aquilegia, Ranunculaceae, basal eudicots), toadflaxes and relatives (Linaria, Plantaginaceae, Asterids; Fig. 2) as well as in orchids (Orchidaceae, monocots). In both Aquilegia and Linaria, spurs develop late in petal ontogeny, and are considered homologous to small nectar-bearing sacs found in identical positions in closely related genera (known as 'gibba' in Antirrhinum and other related genera; Fig. 2A, B) (Cubas et al., 1999; Tucker and Hodges, 2005; Box et al., 2011). In both these systems, spur ontogeny consists of a short phase of cell division generating the spur primordium, followed by a phase of anisotropic cell elongation which is responsible for most of the mature length of the nectar spur (Box et al., 2011; Mack and Davis, 2015). Changes in the relative timing of these phases probably explain the origin of nectar spurs from smaller nectar-bearing sacs, demonstrating that a relatively simple developmental change, added in late ontogenetic stages, can generate morphological novelty that is recurrently linked to outstanding species diversification as a result of its influence on plant-pollinator interactions (Fig. 2C). Some morphological differences suggest that the developmental programmes underpinning spur development may be subtly different between Aquilegia and Linaria: for example, the position of the nectary itself is very different within these the two systems. In Aquilegia the nectary is positioned at the base of the spur, and is thought to act as an organising centre for the 
developing spur. In Linaria the nectary is located on the ovary wall, from where the nectar drains into the spur.

Evolutionary changes in spur length are instances of heterochrony, i.e. changes in the timing of a developmental process (Gould, 1977). Spur length variation across species provides a simple model with which to investigate the developmental basis of both forms of heterochrony: the evolutionary shortening of the spur is a case of early cessation or reduced rate of growth (paedomorphosis), while evolution of a longer spur from a short-spurred ancestor is a case of increased duration or rate of the growth phase (peramorphosis) (Box and Glover, 2010). For example, spur reductions in orchids of subtribe Orchidinae have been interpreted as cases of paedomorphosis caused by an earlier offset of growth (Box et al., 2008). Interestingly, the dramatic variation in spur length across species of Aquilegia is almost exclusively the result of heterochronic changes in the duration of anisotropic cell elongation (Puzey et al., 2011).

The genetic basis of spur development and evolution is still poorly understood. Recent evidence from Linaria and the closely related, though spurless, Antirrhinum indicates a role of KNOTTED1-like homeobox (KNOX) genes during early spur development (Golz et al., 2002; Box et al., 2011). KNOX genes are involved in the maintenance of the shoot apical meristem in vascular plants, among other functions (Hay and Tsiantis, 2010). Golz et al. (2002) described dominant gain-of-function mutations at $K N O X$ loci that generate a petal outgrowth resembling a nectar spur in Antirrhinum (Fig. 2D). An ortholog of one of these genes in Linaria (LvHirz) is highly expressed in the spur-bearing ventral petal during early spur development (Box et al., 2011), and its constitutive expression was found to induce ectopic petal outgrowths in transgenic tobacco (Box et al., 2011) (Fig. 2D). This is congruent with a model in which $K N O X$ activity has been co-opted to promote and maintain further morphogenetic potential during late stages of petal development. Interestingly, recent transcriptome analysis of the developing Aquilegia spur failed to identify upregulation of KNOX genes, suggesting that this clearly convergent trait develops through different genetic programmes in different species (Yant et al., 2015). Research will determine the ontogenetic mechanisms and genetic machinery that have been recurrently recruited to generate nectar spurs and modulate their length in distant angiosperm lineages.

\section{DEVELOPMENTAL MECHANISMS UNDERLYING FLORAL HOMOPLASY}

Here we explore how comparative developmental data can provide insights into homoplastic patterns of floral trait evolution by selecting traits that show exceptional levels of lability across the angiosperms. We begin with the transition to flowering and move progressively from the organismal to the cellular scale exploring: the developmental mechanisms underlying repeated gain of petals across angiosperms, the use of developmental data to refine our understanding of loss versus gain of petals and the mechanisms underlying the evolution of zygomorphy and conical petal epidermal cell formation.

\section{The Transition to Flowering}

In a given habitat, distinct species can flower at very different times while individuals from the same species tend to flower simultaneously. This behaviour has important consequences for reproductive success and fitness, therefore has adaptive potential. First, co-flowering species could compete with each other to attract pollinator attention (exploitative competition), resulting in both species reducing fitness. Secondly, the pollen of the 'wrong' species is more likely to reach a given flower when multiple species are blooming simultaneously (interference competition). Shifting flowering time is therefore a strategy used to minimise competition for pollinator attention.

The transition to flowering is a complex trait in response to a set of environmental and endogenous stimuli (Amasino, 2010). Four main pathways contribute to a plant's decision to flower: the photoperiodic pathway (perception of red and far red light by the plant to measure the length of night/day), the vernalization pathway (perception of winter), the autonomous pathway and the gibberellin pathway (age and physiological status of the individual). These are supported by the 
recently described ambient temperature pathway (Verhage et al., 2014)These pathways act in combination to counteract the floral inhibition pathway, which keeps the plant in the vegetative phase and prevents flowering when conditions are suboptimal (Simpson and Dean, 2002). On a molecular level, the transition to flowering is controlled by an elaborate regulatory network and several excellent reviews have recently synthesized our current knowledge of this intricate genetic circuit (Jung and Müller, 2009; Huijser and Schmid, 2011; Andrés and Coupland, 2012). For the purpose of our discussion, we will focus on key proteins known as flowering-time integrators that integrate signals from these different pathways. Three main integrators have been identified in Arabidopsis thaliana: FLOWERING LOCUS T (FT) (Pin and Nilsson, 2012), SUPPRESSOR OF OVEREXPRESSION OF CONSTANS 1 (SOC1) (Lee and Lee, 2010) and LEAFY (LFY) (Moyroud et al., 2010). The different pathways converge to activate directly, or indirectly via repression of the flowering inhibitor FLOWERING LOCUS C (FLC), the expression of the flowering time integrators: gibberellins promote flowering by antagonizing DELLA-domain proteins, which repress the expression of SOC1 and $L F Y$ (Achard et al., 2004)Ueguchi-Tanaka et al., 2005), while gene networks that perceive light and circadian rhythm converge to activate the expression of $F T$ in the leaves (Kobayashi et al., 1999; Valverde et al., 2004). The FT protein, also known as florigen, then transits to the shoot apex where it promotes the formation of floral meristems by activating expression of $S O C 1$ and then $L F Y$ (Corbesier et al., 2007). Once the expression of the flowering-time integrators exceeds a threshold flowering is initiated in an irreversible manner (Tooke et al., 2005).

Comparative developmental approaches focusing on different groups of angiosperms have recently pinpointed both divergences and conserved elements within the four pathways that control flowering. Indeed, while homologues of key molecular actors (such as FT, LFY, TFL1 or other genes upstream in the pathways) have been found to participate in the control of flowering in an increasing range of angiosperms, differences in their expression patterns or in their biochemical properties help explain what makes flowering time labile and how two distinct species can flower at different times. For example, Arabidopsis flowering is generally promoted by long days and prolonged cold (Greenup et al., 2009), while other species such as rice start producing flowers when days are short and do not need to experience cold to flower (short-day plants). This is because the $F T$ homolog in rice, $H d 3 a$ (Heading date $3 a$ ), is expressed in short days and not long days as in Arabidopsis (Kojima et al., 2002; Tamaki et al., 2007). Thus, evolutionary rewiring of an otherwise conserved photoperiodic pathway can reverse the photoperiod response. Molecular tinkering of a conserved gene network can also explain how closely related and co-occurring species can achieve asynchronous flowering; in the genus Mimulus, for example, M. guttatus flowers in summer while $M$. nasutus flowers in early spring. Quantitative trait locus mapping using hybrids between these two species identified two genomic regions that together account for over 95\% of the divergence between the two Mimulus species in their ability to flower under short days. Interestingly, 3 homologs of SHORT VEGETATIVE PHASE $(S V P)$, a repressor of $F T$ in Arabidopsis, are present in one of these regions. An attractive hypothesis is that $M$. nasutus could carry non-functional alleles of these $S V P$ homologs, explaining its early flowering behaviour (Fishman et al., 2014) but further investigations are required to determine if this region does encode malfunctioning SVP proteins.

More recently, several studies have singled out loci that have major effects on flowering time variation between natural populations of the same species (Brachi et al., 2010; Salomé et al., 2011; Albani et al., 2012; Friedman and Willis, 2013). Interestingly, differences in behaviour depend only on a few genomic regions that often map to key genes from the regulatory network that controls flowering. For example, natural populations of alpine rock-cress (Arabis alpina) differ in the duration of their flowering season: some require vernalization and flower for a limited period while others flower continuously without requiring prolonged exposure to cold. A detailed study of five accessions that do not require prolonged exposure to cold to flower revealed that each carries a different mutated allele of PEP1, the homolog of FLC in A. alpina (Albani et al., 2012). This suggests that PEPl has been repeatedly targeted by selection on flowering time variation and, furthermore, that this flowering behaviour in A. alpina evolved multiple times independently from a common vernalization-sensitive ancestor. Similarly, day neutral and long-day varieties have evolved several times independently from short-day plants in both wild and domesticated sunflowers (Helianthus annuus) (Blackman et al., 
2010; 2011; Blackman, 2013). At least four homologs of FT (HaFT1 to HaFT4) are present in the sunflower genome. A frameshift mutation in HaFTl, extending the protein length by 17 amino acids, experienced selection during early domestication of the sunflower. This new HaFTl allele causes later flowering by producing a dominant negative form that antagonizes the other FT paralogues (Blackman et al., 2011). Additionally, in most sunflower populations HaFT homologs are not expressed in long days, consistent with a short-day response. However in Manitoba, a day neutral population, HaFT4 was also found to be expressed in long days. The ability of individuals from Manitoba to express an FT homolog in both short and long days could account for the day neutrality of this population. Other key factors of the network that regulate flowering have also been shown to be involved in the evolution of phenotype: for example a homolog of SOCl, HaSOCla, is dramatically upregulated $(>x 80)$ in the shoot apex of a sunflower population from Texas (long-day flowering) in response to long-day conditions but not in a population from Kansas that has retained the ancestral short-day flowering behaviour (Blackman et al., 2011).

Taken together, these studies exemplify how gene duplication, followed by mutation of the protein sequence or changes in the expression pattern of key flowering time regulators, can demonstrably contribute to shifts in flowering time between distantly related species, co-occurring species belonging to the same genus, or even between distinct populations of the same species. Such parallel transitions in flowering behaviour are genetically distinct as the molecular mechanisms used by plants to alter their reproductive transition are often species- or even population-specific but can be revealed by adopting a comparative developmental approach.

\section{Distinguishing Convergent versus Parallel Evolution of Petals}

The majority of angiosperm flowers produce two whorls of sterile, protective perianth organs, often, but not always, differentiated into protective green sepals and attractive petals. The differentiation of the perianth has evolved numerous times across flowering plants (Ronse De Craene, 2013). Petals have been lost and gained many times, have been derived from either bracts or stamens (Kramer and Irish, 2000), and occur in a homoplastic pattern across angiosperms.

Prior to the emergence of comparative developmental genetics there had been little discussion of the possibility of common mechanisms underlying these separate origins of petal evolution. However, advances in our developmental genetic understanding of petal formation have raised the possibility of parallel evolution, here defined as the separate evolution of traits underlain by similar genetic pathways. Specifically, the B-class MADS-box genes, known as APETALA3 (AP3) and PISTILLATA $(P I)$ in Arabidopsis, have been shown to be of particular importance in terms of petal development: (1) B-class MADS-box genes are generally expressed in the second whorl petals of a differentiated perianth in core eudicots (Kim et al., 2004; 2005; de Craene, 2007). (2) Activity of B-class MADSbox genes is necessary for development of the petal in the second whorl of the flower (Mizukami and Ma, 1992; Jack et al., 1994; Goto and Meyerowitz, 1994). (3) Persistent activity of B-class MADSbox genes through late stages of petal development is necessary to maintain the expression of characteristic petal features (Bowman, 1991; Zachgo et al., 1995). (4) Heterotopic expression of Bclass MADS-box genes in the first-whorl sepals of the flower is sufficient to induce ectopic petal morphology (Coen \& Meyerowitz, 1991; Krizek \& Meyerowitz, 1996). Given these observations from distantly related core eudicot taxa, it has been proposed that a petal identity program regulated by B-class MADS-box gene homologs arose early in the evolution of angiosperms (Kramer \& Jaramillo 2005), and many studies have subsequently sought to determine if independent derivations of petals are underlain by this common developmental genetic pathway.

However there are numerous examples of petaloid organs whose development may not depend on Bclass MADS-box genes. For example, AP3 and PI homologs are not expressed in the outermost petaloid perianth whorl in flowers of the monocot Asparagus (Park et al., 2003; 2004) and a PI homolog is required for petal identity in the second whorl but not the petaloid first whorl in the basal eudicot Aquilegia (Kramer et al., 2007) despite expression in both whorls. Similarly, the petaloid sepals of Rhodochiton atrosanguineum (Plantaginaceae) do not show any B-gene expression, although they superficially resemble the petals of the same species (Landis et al., 2012). Brockington 
et al. (2011) demonstrated that, at least for some Caryophyllales, petaloid structures in the flower can have an alternative genetic structure that is not dependent on AP3 and PI, supporting the hypothesis of a novel acquisition of petals in the clade (Brockington et al., 2009). In Aizoaceae the perianth is either undifferentiated (eg. Sesuvium portulacastrum) or differentiated into sepals and numerous (staminodial) petals (eg. Delosperma napiforma). In Delosperma the staminodial petals behave as expected for stamens in the early expression of $A P 3, P I$ (B genes) and $A G$ (C gene) before these genes are turned off. However, the petaloid tepals of Sesuvium do not show any expression of $A P 3$ and $P I$, suggesting a novel acquisition of petaloidy in the sepal-derived perianth independent of B-class genetic programs (Fig. 3).

In the future, comparative transcriptomic analysis in a subset of these species should allow us to unveil new molecular determinants of petaloidy, distinct from the classic B-class program, and inform our understanding of petal evolution as a whole during angiosperm evolution. Important advances in understanding petal evolution will depend to a degree on moving away from the B-gene paradigm that has dominated much of the floral evo-devo literature.

\section{Re-Interpreting Direction of Petal Evolution}

Petals have long been regarded as evolutionarily advantageous because they are showy and attractive organs that can facilitate pollination, however recent developmental genetic analyses have revealed patterns of evolutionary loss of petals in Ranunculaceae. Genera within this family typically have petaloid sepals, but vary with regard to the presence or absence of nectiferous petals in the second whorl. The intercalation of apetalous and petalous species led botanists to propose that petals have evolved numerous times through the sterilisation and lamination of stamens. More recent reconstructions, however, tend to support the idea that having petals is an ancestral character state whereas the apetalous condition is derived. In seeking to test this hypothesis, several studies have applied comparative developmental genetic data to better understand the direction and frequency of transitions in petal evolution within Ranunculaceae

Kramer et al. (2003) identified homologs of the AP3 and PI MADS-box genes across Ranunculaceae and showed that an ancient $A P 3$ duplication within Ranunculales gave rise to three distinct AP3 lineages AP3-I, AP3-II, and AP3-III (Kramer et al., 2003). It was subsequently shown that the AP3-III orthologs are specifically expressed in petal organs across the family (Rasmussen et al., 2009). Further functional analyses within the genus Aquilegia showed that the AP3-III paralogue is critical for petal morphology (Sharma et al., 2011). Given these data, in order to invoke independent petal derivation, one would have to assume that the same $A P 3$ paralogue was recruited repeatedly to specify petal development, despite three paralogs being available for recruitment. Consequently it was suggested that ancient sub-functionalisation led to a petal-specific AP3-III function, which has been lost in association with the apetalous condition (Sharma et al., 2011). Further support for this hypothesis comes from analysing the fate of AP3-III orthologs in apetalous genera. Zhang et al. (2013) showed that in many instances of apetaly, expression of the AP3-III ortholog has been decreased or eliminated by species-specific mutations. For example, insertion of a transposable element has led to the silencing of AP3-III, and in several apetalous exemplars the AP3-III gene has been lost altogether or disrupted by deletions in coding or regulatory regions (Zhang et al., 2013). Therefore, the AP3-III gene has been down-regulated by different mechanisms in different evolutionary lineages. Taken together, these data strongly support multiple losses of petals rather than independent gains in Ranunculaceae (Zhang et al., 2013).

This case study from Ranunculaceae emphasises that petal loss may also be advantageous, not least because the formation of petals and nectaries requires resources. Petals may not be advantageous when resources are limited and pollination is generalised, particularly in Ranunculaceae where the sepals are often highly attractive (Zhang et al., 2013). Here, comparative developmental genetic data have clarified our understanding of petal evolution and emphasised the phenomenon of petal loss versus the widely adopted concept of re-iterative petal gain. 


\section{Common Mechanisms Underlying Switches in Floral Symmetry}

Flowers are usually either radially symmetric (actinomorphic) or bilaterally symmetric (zygomorphic). Zygomorphy is a highly labile trait, thought to have evolved up to seventy times independently within the flowering plants (Citerne et al., 2010). Fossil and phylogenetic evidence tell us that ancestral floral forms were actinomorphic and that zygomorphic forms started to arise about 70 million years ago (Crepet, 1996), probably around the same time as the radiation of specialised pollinating insects. Zygomorphic flowers segregate the pollinator community by encouraging approach from a particular direction, as well as by influencing floral handling and pollen placement, (Sargent, 2004). It has been suggested that these behavioural and mechanical differences promote speciation and specialisation in bilaterally symmetric flowers, a hypothesis that is supported by the species richness of families such as Asteraceae (daisies), Orchidaceae (orchids) and Fabaceae (legumes)

The mechanistic basis for floral zygomorphy was first defined in the model zygomorphic species Antirrhinum majus (Plantaginaceae). Experiments using transposon-induced actinomorphic Antirrhinum mutants first identified the genes CYCLOIDEA (CYC) and DICHOTOMA (DICH) as regulators of dorsal identity within the floral meristem (Luo et al., 1996; 1999). CYC and DICH are recent duplicates which code for a pair of TCP family transcription factors that activate dorsalspecific expression of RADIALIS (RAD), encoding a MYB transcription factor (Corley et al., 2005; Costa et al., 2005). Similarly, ventral organ identity is determined by the actions of DIVARICATA (DIV), another MYB transcription factor (Almeida et al., 1997; Galego and Almeida, 2002). RAD negatively regulates DIV function in dorsal parts of the flower by competing with DIV proteins to form heterodimers with common target MYB proteins called DRIFs (Raimundo et al., 2013).

Evo-devo studies of flower symmetry have focused on $C Y C$ homologs, and have so far paid less attention to the downstream network of interacting MYB proteins. $C Y C$ itself arose from a duplication within the $T C P$ gene family at the base of the eudicots and is dorsally expressed in flowers even of angiosperm families with few or no zygomorphic species (Howarth and Donoghue, 2006). The presence of this transcriptional regulator with an ancestrally dorsal expression pattern in the genomes of all eudicots can be thought of as an exaptation, and may explain the frequent evolution of zygomorphy. A wide range of studies have shown that $C Y C$ has been independently recruited in the evolution of zygomorphy multiple times, for instance in the Asteraceae, Brassicaceae, Fabaceae, Dipsacaceae and Malpighiales (Busch and Zachgo, 2007; Kim et al., 2008; Wang et al., 2008; Zhang et al., 2010; Howarth et al., 2011; Hileman, 2014). In addition to frequent gains of zygomorphy, studies have shown that reversals to actinomorphy can be achieved through changes in the regulation of $C Y C$-like genes. In the Fabaceae the majority of genera exhibit zygomorphic flowers but several derived genera, scattered across the phylogeny, have fully radially symmetric flowers. By comparing the actinomorphic flowers of Cadia purpurea to the zygomorphic flower of Lupinus nanus, Citerne et al. (2010) were able to show that actinomorphy had evolved by an expansion of the expression domains of two Cadia CYC genes $\operatorname{Leg} C Y C 1 A$ and $\operatorname{Leg} C Y C 1 B$, from the adaxial into the abaxial and lateral regions of the corolla (Citerne et al., 2010). This suggests that the radial symmetry of the Cadia flower has occurred via dorsalisation of the entire corolla.

Differential expression of $C Y C$ paralogs within an individual plant has been shown to underpin another morphological innovation - the condensed inflorescence with zygomorphic outer flowers and actinomorphic inner ones. This morphology is most pronounced in the capitulum of the Asteraceae. Kim et al. (2008) showed that introgression of zygomorphic outer flowers from Senecio squalidus into Senecio vulgaris (the original form of $S$. vulgaris is entirely composed of actinomorphic disc florets) was brought about by introgression of a cluster of CYC-like genes (Kim et al., 2008). Similarly, in Helianthus (sunflower) mis-expression of a CYC-like gene leads to asymmetric growth of normally actinomorphic disc florets (Chapman et al., 2012).

Although understanding the role of CYC in the development of floral symmetry has provided great insight into the recurrent evolution of zygomorphy, there are a number of puzzles still remaining. The focus on CYC in evo-devo studies means that we do not know whether the key competition between dorsalising and ventralising MYBs observed in Antirrhinum also occurs in independent origins of 
zygomorphy, or whether CYC has been recruited to regulate other genetic modules. Similarly, since CYC arose through a duplication event at the base of the eudicots the focus on it as the primary determinant of zygomorphy has left us with little ability to explain the evolution of bilaterally symmetric flowers outside that clade (except perhaps through recruitment of related TCP proteins) - a striking omission when the orchids (monocots) represent one of the most species rich families of all.

\section{Petal Epidermal Cell Shape}

Petal epidermal cell shape represents an evolutionarily labile trait in which evolutionary transitions are likely associated with flexible genetic regulation by a small sub-family of duplicate transcription factors. The petal epidermis is often formed of conical or papillae-like cells, involved in enhancing attractiveness to pollinators by modifying flower colour, surface texture and grip, floral surface temperature and scent dispersal (Fig. 4) (Glover, 2000; Dyer et al., 2007; Whitney et al., 2009; Glover and Whitney, 2011).

In Antirrhinum majus conical cell formation is regulated by MIXTA, encoding a MYB-related transcription factor, and related genes MIXTA-LIKE 1, MIXTA-LIKE 2 and MIXTA-LIKE 3 (Noda et al., 1994; Glover et al., 1998; Martin et al., 2002; Perez-Rodriguez, 2005; Baumann et al., 2007). This morphology is not only restricted to petals, but can develop on other organs as a result of changes to the expression profile of its regulators. For example, in Thalictrum, a genus with apetalous flowers, conical cells are formed on the petaloid sepals and stamens through MIXTA-like gene activity (Di Stilio et al., 2009).

While comparative developmental approaches have only just started to examine the genetic mechanisms responsible for the patterns of losses and gains of conical cells observed across a family or a genus, more effort has been made to explore the adaptive significance of these evolutionary shifts. Of all floral traits, conical petal epidermal cells are notable for the extent to which developmental genetic tools have allowed detailed dissection of their function. Near isogenic lines developed from transposon insertion mutants in Antirrhinum majus were used to demonstrate that the presence of conical cells increased attractiveness to foraging bees (Glover and Martin, 1998).

Following this work the same lines and various derivatives were used to demonstrate that the positive effect of conical cells on pollinator grip on the flower and the subsequent improvement in the efficiency of foraging was highly significant and likely responsible for the maintenance of the conical cell form on many flowers (Whitney et al., 2009). A number of correlative studies have since shown that the presence of conical epidermal cells on floral organs is related to pollinator type and foraging behaviour. Bee-pollinated flowers, for example, usually present conical cells, while bird-pollinated flowers do not. More detailed analyses of closely related species that have experienced shifts in their major pollinator show that conical petal epidermal cells can be lost and gained relatively frequently within clades. For example, loss of conical cells has been reported in the bird-pollinated Macaronesian species of Lotus (Fabaceae) (Ojeda et al., 2012) and the molecular genetic basis of similar losses in bird-pollinated members of the Antirrhineae, moth-pollinated Nicotiana and buzzpollinated Solanum species are currently under analysis in our lab. These losses are likely due to the ways in which different pollinators interact with flowers, and in particular with the different grip requirements of animals that land compared to those that hover while foraging.

Recent phylogenetic analysis of the subgroup of the MYB transcription factor family containing MIXTA has revealed a duplication within the group at the base of the seed plants, and a further duplication at the base of the eudicots, in addition to a variety of lineage-specific duplications (Brockington et al., 2013) The developmental flexibility provided by multiple semi-redundant transcription factors able to induce cellular outgrowth may explain the evolutionary lability of this highly adaptive floral morphology.

\section{E. CONCLUSIONS}

It is clear that comparative development in synergy with evolutionary analyses represent a powerful approach that has already contributed enormous insight into many different aspects of floral 
evolution. The angiosperm flower is only one example of a trait that has been examined in this way, and similar insights have been gained from evo-devo approaches into the evolution of many other structures, both plant and animal. An analysis of the insights gained reveals that developmental genetic data have often supported evolutionary thinking on novelty and homoplasy, but have also sometimes provided additional insights to test, and they have revealed surprising examples of parallel evolution in many cases. However, there are also gaps in our understanding where developmental genetic approaches have not been able to solve longstanding evolutionary riddles. Where these are apparent it is often the case that a conservative approach to the problem, focusing around known candidate genes and developmental programs, has failed to provide the novel insight required. Such a conservative approach is not surprising, given the cautious nature of many funding bodies, but we hope that the increasing availability of genomic and transcriptomic data for many and varied species will encourage more researchers to develop and use the analytical tools to tackle novel morphologies from an unbiased perspective, providing crucial insight into the development of traits such as independently-evolved petals and nectar spurs.

One of the hallmarks of evo-devo is the diversity of disciplines with which it intersects. Recent efforts to incorporate new approaches promise to help identify new questions, propose new hypotheses and spot novel study systems for developmental studies. From a plant evo-devo perspective, this synergy holds great potential to illuminate our understanding of both macro- and microevolution of flower traits. In addition to the increasing use of genomic and transcriptomic data, we are particularly excited by recent advances in phylogenetic methodologies (Serb and Oakley, 2005) (Minelli, 2009; Laurin and Germain, 2011) and by the incorporation of tools and techniques from population genetics e.g. the elegant work on intraspecific variation and microevolution of zygomorphy in Erysimum mediohispanicum (Gómez et al., 2009). We are confident that the combination of tools and concepts from this broad range of disciplines will continue to see evo-devo studies providing the conceptual framework within which to explain the great diversity of form and function that we see not just in flowers, but throughout the plant and animal kingdoms.

\section{F. ACKNOWLEDGEMENTS}

Work in the Glover laboratory on these topics is funded by the BBSRC, EU Marie Curie Actions, Isaac Newton Trust, Leverhulme Trust, NERC and the NSF, and we gratefully acknowledge all support.

\section{G. REFERENCES}

ACHARD, P., A. HerR, D.C. BAulcombe, AND N.P. HARBERD. 2004. Modulation of floral development by a gibberellin-regulated microRNA. Development 131: 3357-3365.

Albani, M.C., L. Castaings, S. Wötzel, J.L. Mateos, J. Wunder, R. WAnG, M. Reymond, AND G. COUPLAND. 2012. PEP1 of Arabis alpina is encoded by two overlapping genes that contribute to natural genetic variation in perennial flowering. H. Yu [ed.],. PLoS Genetics 8: e1003130.

Almeida, J., M. RocheTA, AND L. GALEGO. 1997. Genetic control of flower shape in Antirrhinum majus. Development 124: 1387-1392.

AMASINO, R. 2010. Seasonal and developmental timing of flowering. The Plant Journal 61: 10011013.

ANDRÉS, F., AND G. COUPLAND. 2012. The genetic basis of flowering responses to seasonal cues. Nature Reviews Genetics 13: 627-639.

ARMBRUSTER, W.S. 1988. Multilevel Comparative Analysis of the Morphology, Function, and 
Evolution of Dalechampia Blossoms. Ecology 69: 1746.

ARMBRUSTER, W.S. 1992. Phylogeny and the Evolution of Plant-Animal Interactions. Bioscience 42: $12-20$.

ARTHUR, W. 2000. Intraspecific Variation in Developmental Characters: The Origin of Evolutionary Novelties. Integrative And Comparative Biology 40: 811-818.

BAUM, S.F., Y. EsHED, AND J.L. BOWMAN. 2001. The Arabidopsis nectary is an ABC-independent floral structure. Development 128: 4657-4667.

Baumann, K., M. Perez-Rodriguez, D. Bradley, J. Venail, P. Bailey, H. Jin, R. Koes, et Al. 2007. Control of cell and petal morphogenesis by R2R3 MYB transcription factors. Development 134: $1691-1701$.

BLACKMAN, B.K. 2013. Interacting duplications, fluctuating selection, and convergence: the complex dynamics of flowering time evolution during sunflower domestication. Journal Of Experimental Botany 64: 421-431.

BlACKMAN, B.K., J.L. STRASBURG, A.R. RADUSKI, S.D. MiCHAELS, AND L.H. RIESEBERG. 2010. The role of recently derived FT paralogs in sunflower domestication. Current biology: CB 20: 629-635.

BlaCKMAN, B.K., S.D. Michaels, AND L.H. RIESEBERG. 2011. Connecting the sun to flowering in sunflower adaptation. Molecular Ecology 20: 3503-3512.

BowmAn, J.L. 1991. Expression of the Arabidopsis Floral Homeotic Gene AGAMOUS Is Restricted to Specific Cell Types Late in Flower Development. THE PLANT CELL ONLINE 3: 749-758.

BOWMAN, J.L., AND D.R. SMYTH. 1999. CRABS CLAW, a gene that regulates carpel and nectary development in Arabidopsis, encodes a novel protein with zinc finger and helix-loop-helix domains. Development 126: 2387-2396.

BOX, M.S., AND B.J. GLOVER. 2010. A plant developmentalist's guide to paedomorphosis: reintroducing a classic concept to a new generation. Trends in Plant Science 15: 241-246.

BoX, M.S., R.M. BATEMAN, B.J. GLOVER, AND P.J. RUDALL. 2008. Floral ontogenetic evidence of repeated speciation via paedomorphosis in subtribe Orchidinae (Orchidaceae). Botanical Journal Of The Linnean Society 157: 429-454.

Box, M.S., S. Dodsworth, P.J. Rudall, R.M. Bateman, AND B.J. Glover. 2011. Characterization of Linaria KNOX genes suggests a role in petal- spur development. The Plant Journal 68: 703 714.

Brachi, B., N. Faure, M. Horton, E. Flahauw, A. VazQuez, M. Nordborg, J. Bergelson, et AL. 2010. Linkage and association mapping of Arabidopsis thaliana flowering time in nature. T. F. C. Mackay [ed.],. PLoS Genetics 6: e1000940.

Brockington, S.F., R. Alexandre, J. Ramdial, M.J. Moore, S. Crawley, A. Dhingra, K. HILU, ET AL. 2009. Phylogeny of the Caryophyllales sensu lato: revisiting hypotheses on pollination biology and perianth differentiation in the core Caryophyllales. International Journal Of Plant Sciences 170: 627-643.

BRockington, S.F., R. AlvareZ-Fernandez, J.B. LANDis, K. AlCORn, R.H. WALKER, M.M. THOMAS, L.C. HILEMAN, AND B.J. GLOVER. 2013. Evolutionary analysis of the MIXTA gene 
family highlights potential targets for the study of cellular differentiation. Molecular Biology And Evolution 30: 526-540.

BuchmanN, S.L. 1987. The Ecology of Oil Flowers and their Bees on JSTOR. Annual Review of Ecology and Systematics.

BUSCH, A., AND S. ZACHGO. 2007. Control of corolla monosymmetry in the Brassicaceae Iberis amara. Proceedings Of The National Academy Of Sciences Of The United States Of America 104: $16714-16719$.

Chapman, M.A., S. TANG, D. Draeger, S. NAMBeEsan, H. ShafFer, J.G. BARb, S.J. KNAPP, AND J.M. BURKE. 2012. Genetic Analysis of Floral Symmetry in Van Gogh's Sunflowers Reveals Independent Recruitment of CYCLOIDEA Genes in the Asteraceae G. P. Copenhaver [ed.],. PLoS Genetics 8: e1002628.

ChitTKA, L., AND J.D. THOMSON. 2001. Cognitive ecology of pollination. Animal behaviour and floral evolution ....

Citerne, H., F. JABBOUR, S. NADOT, AND C. DAMERVAL. 2010. The evolution of floral symmetry. Advances in botanical ....

Corbesier, L., C. Vincent, S. Jang, F. Fornara, Q. Fan, I. SEarle, A. Giakountis, et AL. 2007. FT protein movement contributes to long-distance signaling in floral induction of Arabidopsis. Science 316: 1030-1033.

CORLEY, S.B., R. CARPENTER, L. COPSEY, AND E. COEN. 2005. Floral asymmetry involves an interplay between TCP and MYB transcription factors in Antirrhinum. Proceedings Of The National Academy Of Sciences Of The United States Of America 102: 5068-5073.

Costa, M.M.R., S. FoX, A.I. HANNA, C. BAXTER, AND E. CoEN. 2005. Evolution of regulatory interactions controlling floral asymmetry. Development 132: 5093-5101.

CREPET, W. 1996. Timing in the evolution of derived floral characters: Upper Cretaceous (Turonian) taxa with tricolpate and tricolpate-derived pollen. Review Of Palaeobotany And Palynology 90: $339-359$.

CRONK, Q. 2001. Plant evolution and development in a post-genomic context. Nature Reviews Genetics 2: 607-619.

CRONK, Q.C.B., R.M. BATEMAN, AND J.A. HAWKINS. 2002. Developmental Genetics and Plant Evolution. CRC Press.

CUBAS, P., C. VINCENT, AND E. COEN. 1999. An epigenetic mutation responsible for natural variation in floral symmetry. Nature 401: 157-161.

DE CRAENE, L. 2007. Are petals sterile stamens or bracts? the origin and evolution of petals in the core eudicots. Annals of Botany 100: 621-630.

Di STILIO, V.S., C. MARTIN, A.F. SCHULFER, AND C.F. CONNELLY. 2009. An ortholog of MIXTAlike2 controls epidermal cell shape in flowers of Thalictrum. New Phytologist 183: 718-728.

DORNELAS, M.C., AND A.P.M. RoDRIGUEZ. 2005. A Floricaula/Leafy gene homolog is preferentially expressed in developing female cones of the tropical pine Pinus caribaea var. caribaea. Genetics and Molecular Biology 28: 299-307. 
DRESSLER, R.L. 1982. Biology of the Orchid Bees (Euglossini) on JSTOR. Annual Review of Ecology and Systematics.

Dyer, A.G., H.M. Whitney, S.E.J. ARnOLD, B.J. Glover, AND L. ChITTKA. 2007. Mutations perturbing petal cell shape and anthocyanin synthesis influence bumblebee perception of Antirrhinum majus flower colour. Arthropod-Plant Interactions 1: 45-55.

ENDRESS, P., AND B. STEINER-GAFNER. 1996. Diversity and evolutionary biology of tropical flowers.

FAHN, A. 1979. Ultrastructure of Nectaries in Relation to Nectar Secretion. American Journal Of Botany 66: 977.

Fishman, L., A.L. SweIgart, A.M. KenNEY, AND S. CAMPBELl. 2014. Major quantitative trait loci control divergence in critical photoperiod for flowering between selfing and outcrossing species of monkeyflower (Mimulus). New Phytologist 201: 1498-1507.

FRIEDMAN, J., AND J.H. WILLIS. 2013. Major QTLs for critical photoperiod and vernalization underlie extensive variation in flowering in the Mimulus guttatus species complex. New Phytologist 199: $571-583$

FROHLICH, M.W., AND D.S. PARKER. 2009. The Mostly Male Theory of Flower Evolutionary Origins: from Genes to Fossils. dx.doi.org 25: 155.

GALEGO, L., AND J. ALMEIDA. 2002. Role of DIVARICATA in the control of dorsoventral asymmetry in Antirrhinum flowers. Genes \& Development 16: 880-891.

Garay-Arroyo, A., A. Piñeyro-Nelson, B. García-Ponce, M. DE L.P. SÁnchez, And E.R. ALVAREZ-BUYLLA. 2012. When ABC becomes ACB. Journal Of Experimental Botany 63: 2377-2395.

GLOVER, B., AND C. MARTIN. 1998. The role of petal cell shape and pigmentation in pollination success in Antirrhinum majus. Heredity.

GLOVER, B., AND H. WhITNEY. 2011. SpringerLink - Arthropod-Plant Interactions, Volume 5, Number 4. Arthropod-Plant Interactions.

Glover, B., M. Perez-RodrigueZ, AND C. MARTIN. 1998. Development of several epidermal cell types can be specified by the same MYB-related plant transcription factor. Development 125: 3497-3508.

GLOVER, B.J. 2000. Differentiation in plant epidermal cells. Journal Of Experimental Botany 51: 497-505.

GolZ, J.F., E.J. KECK, AND A. HUdSON. 2002. Spontaneous Mutations in KNOX Genes Give Rise to a Novel Floral Structure in Antirrhinum. Current Biology 12: 515-522.

GOTO, K., AND E.M. MEYEROWITZ. 1994. Function and regulation of the Arabidopsis floral homeotic gene PISTILLATA. Genes \& Development 8: 1548-1560.

GoULD, S.J. 1977. Ontogeny and Phylogeny. Harvard University Press.

GÓMEZ, J.M., M. ABDELAZIZ, J. MuÑOZ PAJARES, AND F. PERFECTTI. 2009. HERITABILITY AND GENETIC CORRELATION OF COROLLA SHAPE AND SIZE IN ERYSIMUM MEDIOHISPANICUM. Evolution 63: 1820-1831.

HAY, A., AND M. TSIANTIS. 2010. KNOX genes: versatile regulators of plant development and 
diversity. Development 137: 3153-3165.

HiLEMAN, L.C. 2014. Bilateral flower symmetry--how, when and why? Current Opinion in Plant Biology 17: 146-152.

HoDGES, S.A. 1997. Floral nectar spurs and diversification. International Journal Of Plant Sciences.

HowarTH, D.G., AND M.J. DonOGHUE. 2006. Phylogenetic analysis of the "ECE" (CYC/TB1) clade reveals duplications predating the core eudicots. Proceedings Of The National Academy Of Sciences Of The United States Of America 103: 9101-9106.

Howarth, D.G., T. MARTins, E. Chimney, AND M.J. DonOGHUE. 2011. Diversification of CYCLOIDEA expression in the evolution of bilateral flower symmetry in Caprifoliaceae and Lonicera (Dipsacales). Annals of Botany 107: 1521-1532.

HUIJSER, P., AND M. SCHMID. 2011. The control of developmental phase transitions in plants. Development 138: 4117-4129.

JACK, T., G. FOX, AND E. MEYEROWITZ. 1994. Arabidopsis homeotic gene APETALA3 ectopic expression: transcriptional and posttranscriptional regulation determine floral organ identity. Cell 76: 703-716.

JUNG, C., AND A.E. MÜLLER. 2009. Flowering time control and applications in plant breeding. Trends in Plant Science 14: 563-573.

Kim, M., M.-L. Cui, P. Cubas, A. Gillies, K. Lee, M.A. Chapman, R.J. AbBott, And E. Coen. 2008. Regulatory genes control a key morphological and ecological trait transferred between species. Science 322: 1116-1119.

KiM, S., J. KoH, M. YoO, H. Kong, Y. HU, H. MA, P. Soltis, AND D. SOlTis. 2005. Expression of floral MADS-box genes in basal angiosperms: implications for the evolution of floral regulators. Plant Journal 43: 724-744.

Kim, S., M. Yoo, V. Albert, J. FarRis, P. Soltis, And D. Soltis. 2004. Phylogeny and diversification of B-function MADS-box genes in angiosperms: Evolutionary and functional implications of a 260-million-year-old duplication. American Journal Of Botany 91: 2102-2118.

KoBAYASHI, Y., H. KAYA, K. Goto, M. IWABUCHI, AND T. ARAKI. 1999. A pair of related genes with antagonistic roles in mediating flowering signals. Science(Washington) 286: 1960-1962.

KoJima, S., Y. TAKahashi, Y. Kobayashi, L. Monna, T. SASAKI, T. ARAKI, AND M. YANO. 2002. Hd3a, a rice ortholog of the Arabidopsis FT gene, promotes transition to flowering downstream of Hd1 under short-day conditions. Plant and Cell Physiology 43: 1096-1105.

KRAMER, E., AND V. IRISH. 2000. Evolution of the petal and stamen developmental programs: Evidence from comparative studies of the lower eudicots and basal angiosperms. International Journal Of Plant Sciences 161: S29-S40.

Kramer, E., L. Holappa, B. Gould, M. Jaramillo, D. Setnikov, and P. Santiago. 2007. Elaboration of B gene function to include the identity of novel floral organs in the lower eudicot Aquilegia. Plant Cell 19: 750-766.

KRAMER, E., V. Di STILIO, AND P. SCHLUTER. 2003. Complex patterns of gene duplication in the APETALA3 and PISTILLATA lineages of the Ranunculaceae. International Journal Of Plant Sciences. 
LANDIS, J.B., L.L. BARNETT, AND L.C. HILEMAN. 2012. Evolution of petaloid sepals independent of shifts in B-class MADS box gene expression. Development Genes and Evolution 222: 19-28.

LAURIN, M., AND D. GERMAIN. 2011. Developmental characters in phylogenetic inference and their absolute timing information. Systematic Biology 60: 630-644.

LEE, J., AND I. LEE. 2010. Regulation and function of SOC1, a flowering pathway integrator. Journal Of Experimental Botany 61: 2247-2254.

LeE, J.-Y., S.F. BAuM, J. Alvarez, A. PATEl, D.H. Chitwood, AND J.L. Bowman. 2005. Activation of CRABS CLAW in the Nectaries and Carpels of Arabidopsis. The Plant Cell ... 17: $25-36$.

LuO, D., R. CARPENTER, C. VINCENT, L. COPSEY, AND E. COEN. 1996. Origin of floral asymmetry in Antirrhinum. Nature 383: 794-799.

Luo, D., R. CARPenter, L. COPSEy, C. VinCEnT, J. Clark, AND E. COEN. 1999. Control of organ asymmetry in flowers of Antirrhinum. Cell 99: 367-376.

MACK, J.-L.K., AND A.R. DAVIS. 2015. The relationship between cell division and elongation during development of the nectar-yielding petal spur in Centranthus ruber (Valerianaceae). Annals of Botany 115: 641-649.

MARTin, C., K. BhATt, K. BAUMANN, H. Jin, S. ZACHGO, K. ROBERTS, Z. SCHWARZ-SOMMER, ET AL. 2002. The mechanics of cell fate determination in petals. Philosophical Transactions of the Royal Society B-Biological Sciences 357: 809-813.

MINELLI, A. 2009. Phylo-evo-devo: combining phylogenetics with evolutionary developmental biology. BMC biology 7: 36 .

MIZUKAMI, Y., AND H. MA. 1992. Ectopic expression of the floral homeotic gene AGAMOUS in transgenic Arabidopsis plants alters floral organ identity. CELL-CAMBRIDGE MA- 71: 119-119.

Moyroud, E., E. Kusters, M. MonniauX, R. Koes, AND F. PARCY. 2010. LEAFY blossoms. Trends in Plant Science 15: 346-352.

NoDA, K., B. Glover, P. LinSTEAD, AND C. MARTIN. 1994. Flower Color Intensity Depends on Specialized Cell-Shape Controlled by a Myb-Related Transcription Factor. Nature 369: 661-664.

OJedA, I., A. SANTOS-Guerra, J. CAUJAPÉ-CASTElls, R. JAÉN-Molina, Á. MARRERO, AND Q.C.B. CRONK. 2012. Comparative Micromorphology of Petals in Macaronesian Lotus (Leguminosae) Reveals a Loss of Papillose Conical Cells during the Evolution of Bird Pollination. International Journal Of Plant Sciences 173: 365-374.

PARK, J., Y. ISHIKAWA, R. YOSHIDA, A. KANNO, AND T. KAMEYA. 2003. Expression of AODEF, a Bfunctional MADS-box gene, in stamens and inner tepals of the dioecious .... Plant Molecular Biology.

Park, J., Y. IshiKaWA, T. OChiaI, A. KANNO, AND T. KameYA. 2004. Two GLOBOSA-like genes are expressed in second and third whorls of homochlamydeous flowers in .... Plant and Cell Physiology.

PEREZ-RODRIGUEZ, M. 2005. Development of three different cell types is associated with the activity of a specific MYB transcription factor in the ventral petal of Antirrhinum majus flowers.

Development 132: 359-370. 
PIGLIUCCI, M. 2008. What, if anything, is an evolutionary novelty? Philosophy of Science 75: 887898.

PIN, P.A., AND O. NILSSON. 2012. The multifaceted roles of FLOWERING LOCUS T in plant development. Plant, Cell and Environment 35: 1742-1755.

PuZEY, J.R., S.J. Gerbode, S.A. Hodges, E.M. Kramer, AND L. MAHAdEVAN. 2011. Evolution of spur-length diversity in Aquilegia petals is achieved solely through cell-shape anisotropy. Proceedings of the Royal Society of London B: Biological Sciencesrspb20111873.

Raimundo, J., R. Sobral, P. Bailey, H. Azevedo, L. Galego, J. Almeida, E. Coen, AND M.M.R. COSTA. 2013. A subcellular tug of war involving three MYB-like proteins underlies a molecular antagonism in Antirrhinum flower asymmetry. The Plant Journal 75: 527-538.

RASMUSSEN, D.A., E.M. KRAMER, AND E.A. ZIMMER. 2009. One size fits all? Molecular evidence for a commonly inherited petal identity program in Ranunculales. American Journal Of Botany 96: 96-109.

Ronse De CRAENE, L. 2013. Origin and evolution of petals in angiosperms. Plant Ecology and Evolution 146: 5-25.

RudAll, P.J., J. Hilton, F. VERGARA-SilVA, AND R.M. BATEMAN. 2011. Recurrent abnormalities in conifer cones and the evolutionary origins of flower-like structures. Trends in Plant Science 16: $151-159$.

Rutledge, R., S. Regan, O. Nicolas, P. Fobert, C. Côté, W. Bosnich, C. KAUffeldT, et AL. 1998. Characterization of an AGAMOUS homologue from the conifer black spruce (Picea mariana) that produces floral homeotic conversions when expressed in Arabidopsis. Plant Journal 15: 625-634.

SAlOMÉ, P.A., K. Bomblies, R.A.E. LAitinen, L. YANT, R. MotT, AND D. WeIGEl. 2011. Genetic architecture of flowering-time variation in Arabidopsis thaliana. Genetics 188: 421-433.

SARGENT, R.D. 2004. Floral symmetry affects speciation rates in angiosperms. Proceedings of the Royal Society of London B: Biological Sciences 271: 603-608.

SCHMID, R. 1988. Reproductive versus Extra-Reproductive Nectaries: Historical Perspective and Terminological Recommendations. Botanical Review 54: 179-232.

SERB, J.M., AND T.H. OAKLEY. 2005. Hierarchical phylogenetics as a quantitative analytical framework for evolutionary developmental biology. BioEssays 27: 1158-1166.

Sharma, B., C. GuO, H. Kong, AND E.M. KRAMER. 2011. Petal- specific subfunctionalization of an APETALA3 paralog in the Ranunculales and its implications for petal evolution. New Phytologist 191: 870-883.

SHINDO, S., K. SAKAKIBARA, R. SANO, K. UEDA, AND M. HASEBE. 2010. Characterization of a FLORICAULA/LEAFY Homologue of Gnetum parvifolium and Its Implications for the Evolution of Reproductive Organs in Seed Plants. International Journal Of Plant Sciences 162: 1199-1209.

SIMPSON, G.G., AND C. DEAN. 2002. Arabidopsis, the Rosetta stone of flowering time? Science 296: $285-289$.

Soltis, D.E., H. MA, M.W. Frohlich, P.S. SOltis, V.A. AlBert, D.G. OPPEnHEIMER, N.S. 
ALtMAN, ET AL. 2007. The floral genome: an evolutionary history of gene duplication and shifting patterns of gene expression. Trends in Plant Science 12: 358-367.

SUNDSTRÖM, J., AND P. ENGSTRÖM. 2002. Conifer reproductive development involves B-type MADS-box genes with distinct and different activities in male organ primordia. Plant Journal 31: 161-169.

TAMAKI, S., S. MATSUO, H.L. Wong, S. YoKOI, AND K. ShImAMOTO. 2007. Hd3a protein is a mobile flowering signal in rice. Science 316: 1033-1036.

TANDRE, K., M. SVEnson, M.E. SVEnSSON, AND P. ENGSTRÖM. 1998. Conservation of gene structure and activity in the regulation of reproductive organ development of conifers and angiosperms. The Plant Journal 15: 615-623.

ToOKe, F., M. ORdidge, T. ChIURUgwi, AND N. BATtey. 2005. Mechanisms and function of flower and inflorescence reversion. Journal Of Experimental Botany 56: 2587-2599.

TUCKER, S.C., AND S.A. HodGES. 2005. Floral Ontogeny of Aquilegia, Semiaquilegia, and Enemion(Ranunculaceae). International Journal Of Plant Sciences 166: 557-574.

Valverde, F., A. Mouradov, W. Soppe, D. Ravenscroft, A. SAmach, ANd G. Coupland. 2004. Photoreceptor regulation of CONSTANS protein in photoperiodic flowering. Science 303: 1003 1006.

VÁzquez-Lobo, A., A. CARlsbecker, F. Vergara-Silva, E.R. AlvareZ-BuYlla, D. PiÑERo, AND P. ENGSTRÖM. 2007. Characterization of the expression patterns of LEAFY/FLORICAULA and NEEDLY orthologs in female and male cones of the conifer genera Picea, Podocarpus, and Taxus: implications for current evo-devo hypotheses for gymnosperms. Evolution \& Development 9: 446-459.

VERHAGE, L., G.C. ANGENENT, AND R.G.H. IMMINK. 2014. Research on floral timing by ambient temperature comes into blossom. Trends in Plant Science 19: 583-591.

WAKE, D.B., M.H. WAKE, AND C.D. SPECHT. 2011. Homoplasy: from detecting pattern to determining process and mechanism of evolution. Science 331: 1032-1035.

WANG, Z., Y. LUO, X. LI, L. WANG, S. XU, J. YANG, L. WENG, ET AL. 2008. Genetic control of floral zygomorphy in pea (Pisum sativum L.). Proceedings of the National Academy of Sciences 105: 10414-10419.

WeSt-Eberhard, M.J. 2003. Developmental Plasticity and Evolution. Oxford University Press.

WhiPPle, C.J., M.J. ZANIS, E.A. KellogG, AND R.J. SCHMIDT. 2007. Conservation of B class gene expression in the second whorl of a basal grass and outgroups links the origin of lodicules and petals. Proceedings Of The National Academy Of Sciences Of The United States Of America 104: $1081-1086$.

WhitNey, H.M., L. ChitTKA, T.J.A. BRUCE, AND B.J. GLOVER. 2009. Conical epidermal cells allow bees to grip flowers and increase foraging efficiency. Current biology : $C B$ 19: 948-953.

WhitTALL, J.B., AND S.A. HodGES. 2007. Pollinator shifts drive increasingly long nectar spurs in columbine flowers. Nature 447: 706-709.

Winter, K.-U., C. Weiser, K. Kaufmann, A. Bohne, C. Kirchner, A. Kanno, H. SAedler, AND G. THEIßEN. 2002. Evolution of class B floral homeotic proteins: obligate heterodimerization 
originated from homodimerization. Molecular Biology And Evolution 19: 587-596.

YAnt, L., S. Collani, J. PuZey, C. LeVy, AND E.M. KRAMER. 2015. Molecular basis for threedimensional elaboration of the Aquilegia petal spur. Proceedings of the Royal Society B: Biological Sciences 282: 20142778-20142778.

YoshidA, H. 2012. Is the lodicule a petal: Molecular evidence? Plant Science 184: 121-128.

Yu, D., M. Kotilainen, E. Pollanen, M. Mehto, P. ElomaA, Y. Helariutta, V.A. Albert, and T.H. TEERI. 1999. Organ identity genes and modified patterns of flower development in Gerbera hybrida (Asteraceae). Plant Journal 17: 51-62.

Zachgo, S., E. Silva, P. MotTe, W. Trobner, H. SAEdLER, AND Z. SchWARZSOMMER. 1995. Functional-Analysis of the Antirrhinum Floral Homeotic Deficiens Gene in-Vivo and in-Vitro by Using a Temperature-Sensitive Mutant. Development 121: 2861-2875.

ZHANG, P., H.T.W. TAN, K.H. PWEe, AND P.P. KUMAR. 2004. Conservation of class C function of floral organ development during 300 million years of evolution from gymnosperms to angiosperms. The Plant Journal 37: 566-577.

Zhang, R., C. GuO, W. Zhang, P. WANG, L. LI, X. DuAn, Q. Du, ET AL. 2013. Disruption of the petal identity gene APETALA3-3 is highly correlated with loss of petals within the buttercup family (Ranunculaceae). Proceedings of the National Academy of Sciences 110: 5074-5079.

ZHANG, W., E.M. KRAMER, AND C.C. DAVIS. 2010. From the Cover: Floral symmetry genes and the origin and maintenance of zygomorphy in a plant-pollinator mutualism. Proceedings of the National Academy of Sciences 107: 6388-6393.

\section{FIGURE LEGENDS}

Fig. 1 A range of floral novelties discussed in this review. A: The flower of Aquilegia sp. with staminodes marked (black arrow). B: The inflorescence of Setaria with many tiny florets ejecting anthers at anthesis (brown speckles) - anthesis is achieved in part by the action of the lodicules. $\boldsymbol{C}$ : Dispersal unit of Taraxacum sp. with the pappus marked (black arrow) $\boldsymbol{D}$ : The flower of Helleborus sp. with its large cup-like nectaries to the outside of stamens (black arrow). $\boldsymbol{E}$ : Inflorescence of Linaria vulgaris, with large floral spurs marked (black arrow)

Fig. 2 Evolution of nectar spurs in Antirrhineae (Plantaginaceae). A: Phylogenetic relationships among Antirrhineae genera (including the sister genus Lafuentea as outgroup) according to Vargas et al. (2014). Character states for corolla base shape (based on Sutton, 1988) are indicated as terminal symbols. All nodes are statistically supported except for those indicated with an asterisk (*). The phylogeny suggests several shifts between entire, gibbous and spurred corolla in the course of Antirrhineae diversification. B: Examples of Antirrhineae species with divergent corolla base shapes, from top to bottom: entire (Mabrya acerifolia), gibbous (Antirrhinum braun-blanquetii) and spurred (Kickxia elatine, Cymbalaria muralis, Chaenorhinum origanifolium, Linaria vulgaris). Gibba and spur are considered homologous. C: Apis mellifera pollinating Linaria viscosa. Pollen is deposited dorsally (white arrow) as a result of the insect foraging the nectar contained in the spur (black arrow). Pollinators are considered the main drivers of nectar spur evolution. D: Evidence for a role of $K N O X$ genes in spur development: Antirrhinum majus KNOX mutant (Hirz-d153, left) with ectopic petal spur (arrow), and transgenic tobacco flowers constitutively expressing an A. majus KNOX protein (35S:AmHirz, right) and displaying ectopic sac-like petal outgrowths (arrow) (modified from Box et al., 2011). 
Fig. 3 Images clockwise from top left. A. Bombus hortorum (garden bumblebee) foraging from a Vicia faba (broad bean) flower. B. Nicotiana noctiflora, a hawkmoth pollinated flower with lenticulate petal epidermal cells. $\boldsymbol{C}$. Scanning electron micrograph image of an Apis mellifera (honey bee) claw. $\boldsymbol{D}$. Scanning electron micrograph image of Nicotiana mutabilis conical petal epidermal cells. E. Scanning electron micrograph image of Nicotiana acuminata flat petal epidermal cells. Scale bars all $50 \mu \mathrm{M}$.

Fig. 4 Examples of separate instances of petal evolution with Caryophyllales. $\boldsymbol{A}$. Petaloid bracts in Bougainvillea glabra. B. Petaloid sepals in Portulaca oleracea. C. Petaloid staminodes in Delosperma napiforme D. Petaloid bracts in Opuntia humifusa. E. Petaloid staminodes in Stellaria media. $\boldsymbol{F}$. Adaxially petaloid tepals in Sesuvium portulacastrum. 